\title{
Alianzas interreligiosas que retan la laicidad en México
}

Recibido: 15 de mayo 2018 Revisado: 11 de setiembre 2018 Aprobado: 20 de setiembre 2018

Reneé de la Torre

Méxicana. ProfesoraInvestigadora del CIESAS Occidente, en Guadalajara, México. Es miembro del

Sistema Nacional de Investigadores (SIN) nivel III y de la Academia de las Ciencias en México. Es cofundadora de la Red de Investigadores del Fenómeno Religioso en México (RIFREM) que, desde 1998, ha celebrado encuentros nacionales anuales, en la cual colabora como miembro de su Comité Académico. Durante su carrera de investigación se ha dedicado al estudio de la diversidad y del cambio religioso en México. Correo electrónico: reneedela@gmail.com

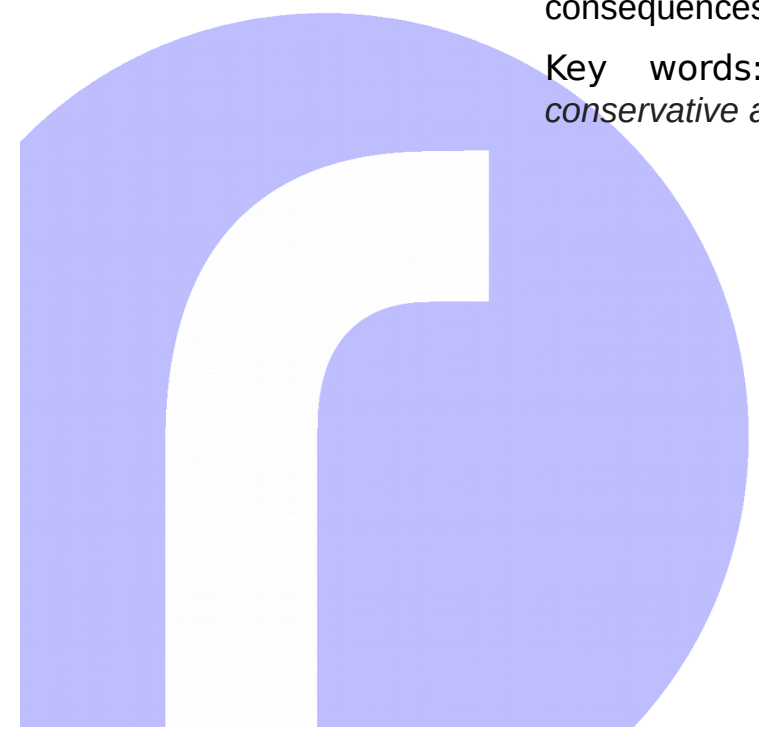

http://investiga.uned.ac.cr/rupturas/ (c) (1) (2)
Resumen: Este ensayo describe la diversificación religiosa en México que conduce a una recomposición de las relaciones religiones y política. Los evangélicos representan un nuevo actor político que desafía a la laicidad; recientemente, han establecido alianzas estratégicas inusitadas que retan a repensar la laicidad para México. El marco constitucional de la laicidad mexicana fue pensado para contener la acción directa de las cúpulas católicas en la política, pero en el presente está rebasado. Este ensayo retoma la propuesta del triángulo equilátero de la laicidad contemporánea de Baubérot (2007) para reflexionar sobre los dilemas y las posibles salidas para lograr una laicidad, que contemplen tanto el pluralismo religioso, la separación Estado-iglesias, como la libertad de conciencia y sus consecuencias.

Palabras clave: Laicidad; pluralismo religioso; México; alianzas conservadoras interreligiosas; evangélicos; católicos

\section{Interfaith Alliances that Challenge Secularism in Mexico}

Abstract: This essay describes the religious diversification in Mexico that leads to a recomposition of religions and politics. Evangelicals represent a new political actor that challenges secularism. Recently they have established unusual strategic alliances that challenge to rethink secularism for Mexico. The constitutional framework of Mexican secularism was thought to contain the direct action of Catholic ducts in politics, but in the present it is exceeded. This essay takes up the proposal of the equilateral triangle of the contemporary secularism of Baubérot (2007) to reflect on the dilemmas and the possible ways to achieve a secularism that contemplates both religious pluralism, State-church separation, and freedom of conscience and its consequences.

Key words: Secularism; religious pluralism; Mexico; interreligious conservative alliances; evangelicals 


\section{Introducción}

¿En qué medida la diversificación religiosa en un país mayoritariamente católico conduce a la salida de lo religioso del espacio público o, por el contrario, al ingreso de nuevos actores disputando la política? ¿Cómo intervienen las religiones en política en un país de tradición laica como lo es México? ¿Qué tipo de política ponen en juego? ¿Cómo se relacionan con los valores de la laicidad contemporánea? Estas preguntas orientan este ejercicio analítico que cobra relevancia en el contexto actual de México, pues, por un lado, la recomposición del campo religioso experimenta un cambio caracterizado por la pérdida del monopolio católico y el ascenso de una vigorosa diversidad religiosa impulsada por las congregaciones cristianas (de tipo bíblicas o paraprotestantes y evangélicas o pentecostales); pero, por otro lado, el campo político se rige con nuevas reglas del juego democrático; por ejemplo, en las actuales elecciones presidenciales, los candidatos usan los recursos religiosos para legitimar las propuestas políticas, rebasando los límites que procura la laicidad.

En el catálogo del Censo mexicano se reconocen bajo la categoría de "Bíblicas diferentes de las evangélicas" a las denominaciones que son sociológicamente conocidas como paraprotestantes. Su distinción y separación del grupo de evangélicos y pentecostales se debe a que son denominaciones cristianas que han agregado otro libro sagrado o partes a la Biblia, como son: Testigos de Jehová, Adventistas del Séptimo Día e Iglesia de Jesucristo de los Santos de los Últimos Días. Estas tres denominaciones comparten un origen histórico común: provienen de la ola adventista de principios del siglo XIX, que tuvo su inicio en Estados Unidos de Norteamérica. Sin embargo, como han mostrado los análisis censales, cada una se ha desenvuelto de manera muy diferente en el territorio mexicano (véase De la Torre y Gutiérrez Zúñiga 2007). El pentecostalismo no es una congregación o denominación religiosa, sino una modalidad religiosa del protestantismo cristiano altamente emocional basada en el reconocimiento de los dones y carismas del Espíritu Santo. Sumadas las denominaciones pentecostales, alcanzan el mayor número de creyentes afiliados a minorías religiosas en México (Garma 2007). El pentecostalismo es una corriente cristiana que está compuesta por diversas denominaciones, algunas ampliamente institucionalizadas, unas más otras que funcionan bajo una dinámica sectaria, basada en rupturas y refundaciones, alianzas y divisiones y otras que establecen alianzas interdenominacionales entre las cuales ocurre una intensa circulación de miembros (Mafra 2013). 
En un ensayo de Pierre Bastian sobre las dinámicas contemporáneas del campo religioso latinoamericano invitaba a reflexionar sobre el impacto de la recomposición del campo religioso, antes monopólicamente católico y en el presente tendiente a la diversidad religiosa, en los reacomodos y redefiniciones del campo político. Retomando los planteamientos del sociólogo Pierre Bourdieu, Bastian planteaba que:

La relación entre campo religioso y campo político: "ordena la configuración de la estructura de las relaciones constitutivas del campo religioso" (Bourdieu 1971, 330). Pero, al mismo tiempo, la transformación de las relaciones dentro del campo religioso por la lógica de la competencia y del mercado empuja a los nuevos actores a intentar movilizar sus recursos en el plano político con el objetivo de modificar la relación de fuerza al interior del mismo campo religioso (Bastian 2011, 32).

La recomposición del campo religioso comienza apenas a experimentarse en México. La población católica en 1950 representaba 98,21 \% del total y en 2010 se redujo a 82,6 \%; mientras que la población disidente, de aquellos que se convirtieron a otras denominaciones, aumentó de 1,79\% en 1950 a 17,4 \% en el año 2010 (XII Censo General de Población y Vivienda 2010).

\section{Figura 1. Composición religiosa en México}

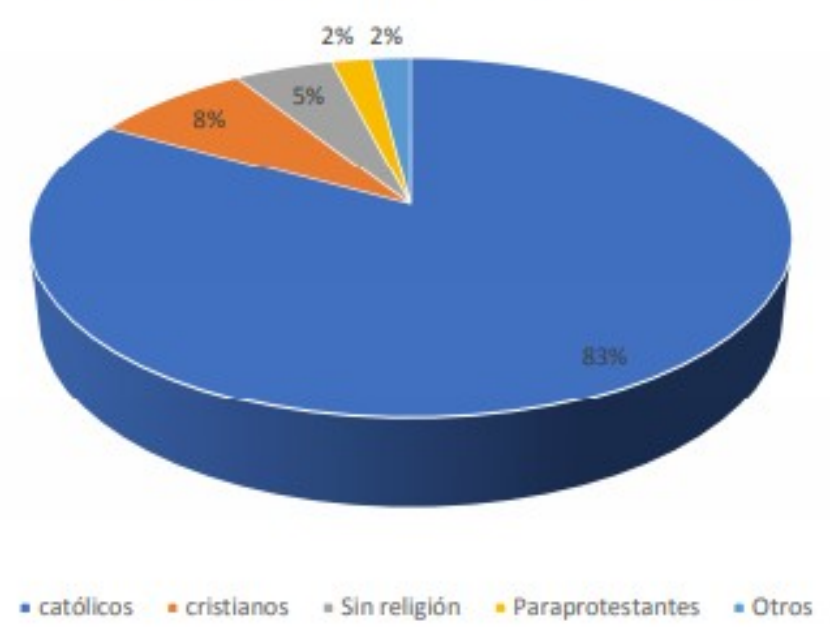

Fuente: INEGI, Censo 2010. 
Aunque ya no se puede hablar de monopolio católico, su estatus mayoritario no permite caracterizar a México como una nación regida por la diversidad religiosa. La mayoría de los cristianos y desafiliados son conversos de primera generación, por tanto, todavía son disidentes católicos y representan una minoría frente a una abrumadora mayoría católica (Gutiérrez Zúñiga y De la Torre 2017). La cifra total de evangélicos reportada por el Censo es de poco más de 7 millones en un país de 120 millones de habitantes.

\section{Figura 2. Distribución porcentual de pertenencia entre cristianos no católicos en México}

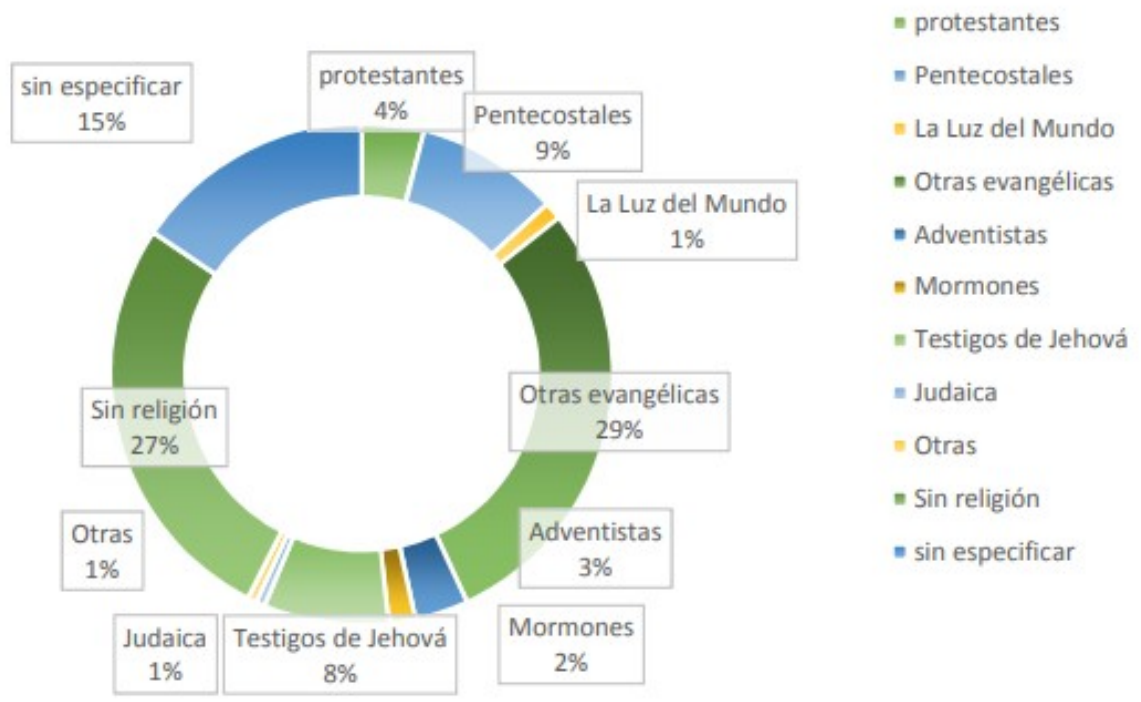

Fuente: INEGI, XII Censo de Población y Vivienda 2010, disponible en http_//www.inegi.org.mx

Si bien en conjunto pudieran representar un número importante para el clientelismo político basado en puestos a cambio de votos seguros, esto no es así porque, como se muestra en la figura 2, que grafica el conjunto de las pertenencias de los cristianos no católicos con los datos censales del 2010, no católicas no están constituidas por un grupo compacto ni mucho menos homogéneo. En él, se agrupan miembros de diferentes denominaciones cristianas, algunas que se reconocen genéricamente como evangélicas, cristianas y pentecostales. Por lo general, los nombres con que los creyentes de una misma denominación se identifican, muchas veces son intercambiables en las congregaciones abiertas a lo interdenominacional. Por ejemplo, los templos de la denominación pentecostal Asambleas de Dios, en la ciudad de Guadalajara, la mayoría no se identifica con la denominación específica; $65 \%$ se identifican como cristianos evangélicos, 23,7 \% como simplemente cristianos, y $2,6 \%$ como cristianos evangélicos pentecostales. Estos datos fueron ofrecidos por la encuesta "Patrón de residencia y comportamiento territorial de centros de culto no católicos en la ciudad de Guadalajara". Se aplicaron 1912 cuestionarios anónimos al término de los servicios religiosos y en las afueras 
del centro de culto, a una muestra de 29 centros de culto, calculada sobre el universo total de los 449 lugares de culto identificados previamente por el proyecto "Directorio de centros de culto no católicos en la ZMG" (Ver Gutiérrez y De la Torre 2015). Por esta razón, a lo largo del ensayo, usaremos de manera indistinta estos nombres. Es importante mencionar también que en las respuestas de adscripción creyente que constituyen los datos censales (que sirven de base del análisis) no existe distinción clara entre cristiano, evangélico o pentecostal. La tipificación se complica, debido a que igualmente encontramos nuevas formas de consumo que no requieren conversión y adhesión, como lo está promoviendo la Iglesia Universal del Reino de Dios, que se publicita como "Pare de sufrir, Santuario de la Fe". Esta iglesia, con importante expansión en México, está generando una modalidad alternativa en la que los asistentes se sienten invitados por la promoción mediática a asistir a cultos para encontrar soluciones milagrosas a sus problemas diarios, sin por ello tener que afianzar su compromiso ni su identificación exclusiva con la institución que los ofrece. Los asistentes a los cultos se identifican solo en una tercera parte con esa religión (33,3\%), pues estos en su mayoría se auto presentaron como católicos (39 \%) y sin religión (12\%) y solamente 14,1 \% como "cristianos" (Gutiérrez Zúñiga y De la Torre 2015).

Además, hay denominaciones con fuertes identidades que no son captables por un partido de corte evangélico y que representan una tercera parte del conjunto de los cristianos. Los asistentes en los lugares de culto de las iglesias Testigos de Jehová, Adventista del Séptimo Día, Iglesia de Jesucristo de los Santos de los últimos Días y La Luz del Mundo comparten modelos de identificación y permanencia con su congregación (Gutiérrez Zúñiga y De la Torre 2015). Entre ellas cabe mencionar a los Testigos de Jehová, la congregación paracristiana con más adeptos en México, presente en todo el territorio nacional, con más de un millón y medio de fieles (XII Censo General de Población y Vivienda, INEGI 2010), que reprueba la injerencia de sus fieles en política. Seguida por los Adventistas del Séptimo Día y los mormones, que son también autónomas. También, encontramos a quienes pertenecen a denominaciones protestantes históricas entre las cuales destacan la iglesia luterana, anglicana, un sector de la bautista, congregacional. Algunas de estas iglesias impulsan agendas liberales, apoyando incluso los matrimonios entre el mismo sexo (Bárcenas 2015). Además, se encuentran entre ellos los seguidores de La Luz del Mundo, la principal congregación mexicana pentecostal, que registra alrededor de 600000 afiliados, pero debido a que promueve un gobierno apostólico en torno al liderazgo del apóstol (el principal líder religioso miembro de un linaje familiar), no se ciñe por gobiernos congregacionales (Barranco 2016) y no establece alianzas con otras iglesias evangélicas, aunque opera de manera autónoma negociaciones clientelares con los gobiernos locales ofreciendo votos a cambio de peldaños políticos para cuadros internos (De la Torre 2000). En suma, los evangélicos no representan un bloque unido.

Cabe agregar que "otras evangélicas" y "pentecostales" agrupan al $68 \%$ del $8 \%$ total de cristianos, pero hacia su interior está conformado de distintas de- 
nominaciones con muchas variedades internas (en tamaño, formas de liderazgo y doctrinalmente). Hay algunos liderazgos internos importantes como el de Asambleas de Dios, la Iglesia Apostólica Mexicana y CONFRATERNICE (que agrupa a algunas iglesias pentecostales) que han desarrollado habilidades para negociar votos por puestos en las cámaras de diputados y de senadores y que lideran el Partido Encuentro Social (PES). También, es necesario contemplar que se compone de varias minorías religiosas, internamente muy dispares y en ocasiones divididas y en competencia entre sí. Por tanto, se puede decir que es una minoría fragmentada. Estas segmentaciones también se aprecian en la manera en que se incorporan al juego político, como se desarrollará líneas más adelante.

Existen, además, otras congregaciones que se articulan en redes interdenominacionales que han optado por fundar el Partido Encuentro Social (PES), el primer partido político formado por evangélicos de distinta índole, que recientemente estableció una alianza partidista con Andrés Manuel López Obrador, el candidato a la presidencia de la República que encabeza al partido MORENA y que ganó las elecciones en junio del 2018.

También, se experimenta un ascenso de población desafiliada que alcanza casi $5 \%$ de la población, que al responder "sin religión" no necesariamente se trata del modelo de ateo o gnóstico, sino principalmente al de buscador de espiritualidades sin iglesia, pero que no representan una facción política.

\section{La recomposición de la laicidad en México}

El nuevo paisaje religioso genera un nuevo contexto más complejo que la oposición Iglesia católica-Estado, que fue reglamentada desde el Estado laico mexicano durante casi todo el siglo XX. En la actualidad, la laicidad es disputada por nuevos actores religiosos y políticos, pero también ingresan a escena otros valores que debe comprender la propia laicidad. ¿Cuánto este nuevo panorama permite a México conformar una laicidad contemporánea acorde al modelo propuesto por Baubérot? Este sociólogo francés propone que la laicidad contemporánea no se reduce a la delimitación de funciones entre el Estado y las religiones, sino que requiere buscar el equilibrio entre las tensiones que participan en un "triángulo casi equilátero, cuyos lados serían la separación de la religión y de la política, la libertad de conciencia y sus consecuencias, y la igualdad entre las religiones" (Baubérot 2007).

A continuación, desarrollaré cómo en la nueva situación nacional, enmarcada por la diversidad religiosa, la laicidad, conceptualizada en las tres dimensiones antes referidas, se convierte en un complejo campo de tensiones. 
Figura 3. Triángulo equilátero de la laicidad propuesto por Baubérot (2007)

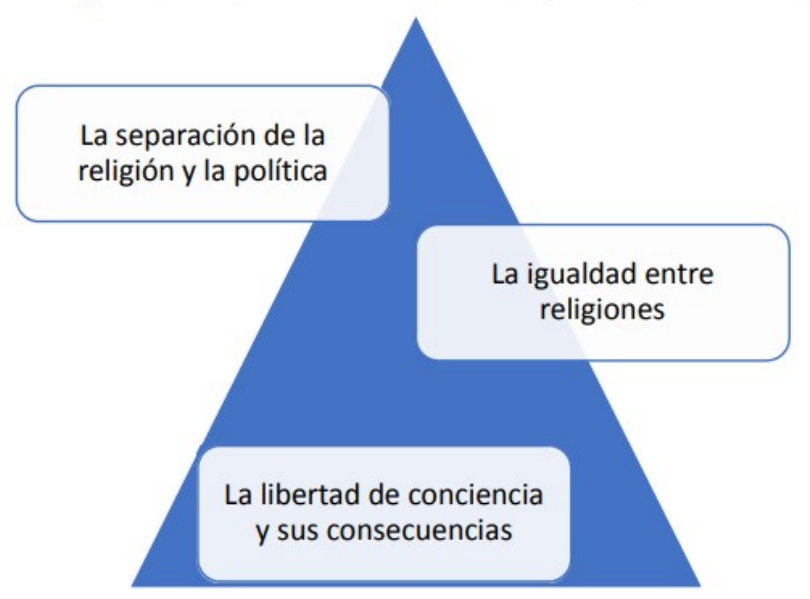

\section{La separación de la religión y la política.}

México es un país que tiene un marco de laicidad que comprende leyes para delimitar la influencia de las religiones áreas neurálgicas del espacio público (salud, educación, política partidista y medios de comunicación). A principios del siglo XX, el Estado mexicano estableció leyes en su Constitución de 1917, que regulaban y normaban el actuar de la Iglesia católica en varios ámbitos públicos. Varios de dichos artículos eran anticlericales (por ejemplo, se prohibía el voto de los sacerdotes y la práctica pública de la religiosidad, así como que los clérigos y monjas ostentaran sus vestimentas clericales en los espacios públicos. También, se prohibía la educación religiosa en las escuelas (aunque había escuelas religiosas que simulaban no enseñar contenidos confesionales) y las propiedades de las iglesias fueron incautadas por el Estado. También, se prohibía y sancionaba la participación de los sacerdotes y religiosos en política partidista y a quien hiciera comentarios políticos desde el púlpito. En la práctica, algunas de las prohibiciones se hicieron más permisivas, mediante un modus vivendi de simulación (como era el culto público en un país con tradición de peregrinación a los santuarios). Las leyes de laicidad generaron tensiones y conflictos con la Iglesia católica en varias ocasiones; incluso, esta situación llevó a una guerra entre 1926 y 1929 conocida como Guerra Cristera, diferentes asociaciones laicales organizaban cruzadas para reclamar derechos de libertad religiosa (Blancarte 2008).

Este marco legal se mantuvo hasta el año de 1992, cuando se reconocieron jurídicamente la existencia de las asociaciones religiosas. Además, se introdujeron cambios en la Constitución, principalmente, se modificó el artículo 130, que permite el voto de los ministros de culto en el espacio público y las actividades religiosas en las calles. En la actualidad, se mantienen artículos que limitan la educación religiosa en la escuela pública, la restricción de la propiedad de medios de comunicación electrónica y las candidaturas de pas- 
tores o sacerdotes a puestos políticos. Recientemente, en el año 2012, se realizaron nuevas modificaciones sustanciales en la ley y se reconoció explícitamente el carácter laico de la República y cambiando el concepto de libertad de culto por el de libertad religiosa, pero debido a que no se definió este término, la ambigüedad ha abierto la posibilidad de que distintos grupos religiosos justifiquen su intervención abierta en política (Salazar 2015).

Además, la jerarquía católica (me refiero en especial a los obispos y cardenales prominentes que han acaparado la voz autorizada de la Iglesia debido a su estatus de religión mayoritaria y a los nexos que guarda con las cúpulas del poder políticos y empresarial), sigue gozando de tratos extraordinarios y privilegios por parte de las élites políticas (como se pudo apreciar en la pasada visita del papa Francisco a México en febrero de 2016). Con la alternancia política conquistada en 2000 , se vino abajo la tradición política jacobina del Partido Revolucionario Institucional que se mantuvo como una "dictadura perfecta" por alrededor de setenta años. Durante dos sexenios, hubo presidentes que provenían del Partido Acción Nacional, que tuvieron un trato preferencial con los obispos católicos y que defendían los valores provida y por la familia. Otro factor importante es la presencia del Opus Dei y de la congregación de Legionario de Cristo entre las élites políticas y empresariales, tanto en la formación de liderazgos como en su presencia en organizaciones conservadoras de la sociedad civil. Por su parte, los obispos católicos, a través de la Conferencia Episcopal Mexicana, buscan asegurar un trato especial por ser religión mayoritaria y enraizada en las tradiciones. Sumado a ello, las minorías cristianas son ahora más activas para demandar libertades, tratos igualitarios y reconocimientos y accesos a áreas de la esfera pública o política. Pero, su activismo, no solo va en la dirección de conquistar valores pluralistas de respeto y en contra de la discriminación religiosa, sino que, a su vez, recientemente han ingresado en la escena política para inhibir o negar derechos y libertades a otras minorías sociales (como lo es el matrimonio LGBT). Se dificulta con ello una sana laicidad y la práctica de una cultura pluralista. A esto, se añaden figuras políticas de diferentes partidos que han mostrado recientemente su confesionalidad de manera pública. Por ejemplo, Vicente Fox, quien fue primer presidente abiertamente católico en el México moderno, por el Partido Acción Nacional, recibió el estandarte de la Virgen de Guadalupe cuando triunfó electoralmente. Este gesto fue inédito en un país que durante más de 70 años de ejercicio de la dictadura partidista del Partido Revolucionario Institucional (PRI), normaba una cultura jacobina que prohibía las manifestaciones de fe en el espacio público.

El paso hacia la alternancia democrática fue también la apertura hacia las manifestaciones públicas de la fe y el uso de los símbolos religiosos como símbolos nacionales en el espacio público y en política formal. En la actualidad, distintos políticos instrumentan símbolos religiosos para ganar adeptos (crucifijos, vírgenes, biblias, etcétera). También, los agentes religiosos (incluyendo predicadores y pastores evangélicos y laicos católicos) han incrementado su ingreso a la política para convertirla en un terreno de misiones y se busca imponer al resto de la población sus convicciones 
religiosas, sin medir las consecuencias sociales que deberían orientar las decisiones políticas. ${ }^{1}$ Un ejemplo de ello es cuando la alcaldesa de Monterrey (la tercera ciudad en importancia de México) entregó las llaves de la ciudad a Jesús de Nazareth, mencionando que "sin sus presencia y ayuda no podemos tener éxito real"2.

Todavía la Constitución prohíbe el actuar religioso en varias esferas e instituciones de la vida pública como son la escuela laica (sin contenidos religiosos), la no incursión de agentes religiosos (sacerdotes o pastores) en la política partidista y la imposibilidad de que las asociaciones religiosas puedan ser propietarias de los medios de comunicación (en específico de canales de televisión y de radio). Los artículos vigentes de la Constitución mexicana buscan impedir la acción directa de las iglesias en la vida pública. No obstante, como trataré de demostrar, este marco legal es insuficiente y constantemente se ve rebasado por la propia presión de agentes religiosos, tanto católicos como cristianos, que buscan evangelizar las esferas públicas (principalmente la salud, la educación, los temas relacionados con derechos sexuales, las políticas familiares, los contenidos de los medios de comunicación y la actividad política partidista). Esto se debe, como lo señala Roberto Blancarte, a que "La distinción entre público y privado no ha sido nunca ni puede ser ahora absoluta. Pero, las sociedades modernas las fueron demarcando con mayor énfasis, en la medida que el proceso llamado diferenciación social condujo a una situación en la que la religión dejó de estructurar a los otros ámbitos de la vida pública" (Blancarte 2004, 91).

\section{La igualdad entre religiones}

A raíz de la Ley de Asociaciones Religiosas decretada en 1992, México ha experimentado un reacomodo en la definición del papel y los alcances del Estado laico y su relación con las distintas asociaciones religiosas presentes en el país. Dicha ley posibilitó el paso de un país anticlerical a un territorio laico que reconoce jurídicamente la pluralidad de religiones establecidas al admitir su autonomía con respecto al Estado. Además, introdujo el reconocimiento de los derechos de la diversidad religiosa estableciendo el registro de asociaciones y poniendo a funcionar la Subsecretaría de Asociaciones Religiosas, mediante la cual brinda apoyos a la tramitación de actividades de las diversas congregaciones, brinda asesoría jurídica y actúa como intermediaria para solucionar conflictos entre distintos grupos religiosos.

Aunada a la ley, se estableció la Dirección General de Asociaciones religiosas, que actúa como un aparato estatal de regulación sobre las propiedades y las actividades de las asociaciones religiosas. Pero, por otro lado, el reconocimiento a las asociaciones religiosas ha repercutido en un considerable incremento de la visibilidad pública de las asociaciones religiosas (que incluye una mayor proyección de los jerarcas católicos a opinar sobre asuntos políticos de distinta índole, pero también un mayor rejuego de símbolos y discursos religiosos en campañas y actividades meramente políticas, hasta la incorporación de grupos religiosos en el juego de la política partidista). A par-
1. Max Weber (1992) distinguía entre las decisiones políticas tomadas a partir de convicciones religiosas y las decisiones tomadas a partir del cálculo de las consecuencias.

A estas últimas, las

denominaba pensamiento moderno.

2. ideo disponible en https://aristeguinoticias.com/10 06/mexico/video-alcaldesa-demonterrey-entrega-llaves-de-laciudad-a-jesucristo/ 
tir de la década de los noventa del siglo XX, esta situación se transformó cuando se restablecieron las relaciones diplomáticas con el Estado del Vaticano (1991) y con la modificación de las leyes constitucionales que reconocían la existencia jurídica y el comportamiento público de las asociaciones religiosas en México (1992). La ley se conoció como Ley de Asociaciones Religiosas y con ella se flexibilizaron antiguas prohibiciones como fueron la manifestación de la religión en los espacios públicos y el reconocimiento de los derechos ciudadanos de los sacerdotes a votar (González 2001).

\section{La libertad de conciencia y sus consecuencias}

En este apartado es importante subrayar que la libertad de conciencia no solo se refiere a la libertad de creencia religiosa, sino también a la libertad más amplia que incluye el no creer (Baubérot, 2017). La libertad de conciencia se tensa en el nivel moral, donde las versiones conservadoras de los movimientos católicos y evangélicos recientemente han entablado alianzas entre pentecostales y católicos para enfrentar conjuntamente al enemigo común reconocido como la "ideología de género". Este término se usa para etiquetar cualquier esfuerzo por promover la aceptación de la diversidad sexual y de género. Cuando los expertos argumentan que la diversidad sexual es real y la identidad de género es un constructo, el clero evangélico y católico dice que no se trata de algo científico, sino de una ideología. [...] La belleza política de la "ideología de género" es que ha dado a los clérigos una forma de replantear su postura religiosa en términos laicos: como derechos de los padres. En América Latina, el nuevo lema cristiano es: "Con mis hijos no te metas". Es uno de los resultados de esta colaboración entre evangélicos y católicos (Corrales 2018). La libertad de conciencia es también un derecho de los grupos feministas, los colectivos LGBT, las minorías raciales, y las personas con capacidades diferentes. Estos sectores, junto con las religiosidades minoritarias, son los que más sufren de discriminación en México. Sus demandas por el reconocimiento público de su diferencia y por derechos (como es el matrimonio) constantemente entran en tensión moral con las diferentes iglesias conservadoras, ello también genera un campo de tensión y conflicto entre los conservadores y los sectores liberales de la sociedad civil que abanderan derechos laicos y con algunos sectores liberales del gobierno.

Por su parte, un país como México, donde el catolicismo ha gozado de hegemonía a lo largo de siglos, sigue requiriendo de un Estado que arbitre la laicidad. Se requiere que mantenga el trato equivalente entre las diferentes asociaciones religiosas al velar por los derechos a la libertad y la expresión religiosa de todos sin importar credo o carácter minoritario, a fin de que sea un intermediario que evite la discriminación y los tratos preferenciales.

Si bien todas las religiones reclaman el respeto a su creencia particular y ello ha incrementado la cultura pluralista sobre el reconocimiento ciudadano a las minorías religiosas, no ocurre con respecto a la libertad de las creencias y sus manifestaciones rituales de los otros, sobre todo de quienes profesan religiosidades o espiritualidades no institucionalizadas (por ejemplo, el culto a la Santa Muerte o la santería que no han logrado reconocimiento de la Ley 
de Asociaciones Religiosas). La diversidad constantemente activa y reactiva alianzas y oposiciones muy pragmáticas que van en distintos sentidos: a nivel teológico existe una disputa con la Iglesia católica y con las expresiones tradicionales iconográficas (como son las religiosidades y ritualidades indígenas o afroamericanas calificadas de idólatras); frente a las amenazas que les representan los avances de quienes demandan libertad sexual y derechos de género ha producido alianzas insólitas entre evangélicos y católicos conservadores que hoy marchan codo a codo para enfrentar a la llamada "ideología de género".

\section{La esfera pública como tierra de misiones de las religiones}

La laicidad mexicana estuvo pensada como un contenedor de la acción de la institución católica en las instituciones políticas que conforman el Estado, principalmente en las áreas de política formal partidista, en la salud, en la educación y en las políticas de población.

\section{Católicos}

La Iglesia católica, a pesar de haber experimentado una secularización interna, es una institución con un modelo de organización basado en una estructura jerárquica, piramidal y territorial. Las leyes de la constitución buscan establecer un marco de regulación gubernamental de la acción directa de la jerarquía católica.

Si bien el catolicismo no es una entidad homogénea, sino más bien diversa tanto en modelos de creer como en modelos de pastoral que animan el activismo social y político, también es verdad que en la actualidad solo el sector conservador tiene capacidad organizativa y representa "el brazo derecho de la jerarquía mexicana". La cúpula de la Iglesia católica es contundentemente conservadora. Debido a las leyes laicas que prohíben el actuar público de los sacerdotes, han tenido injerencia en asuntos públicos mediante el apoyo de movimientos cívicos laicales que han emprendido a lo largo de la historia del siglo XX y el XXI cruzadas, boicots, marchas, campañas para defender la vigencia de valores conservadores (De la Torre 2008). En muchas ocasiones, se han organizado para oponerse a políticas liberales que contravienen los principios y los valores que sustentan el orden patriarcal de la familia tradicional católica (recientemente se han opuesto a la promoción del condón, de la píldora del día siguiente, a la despenalización del aborto y en el presente a la iniciativa de ley de matrimonio igualitario).

Por otra parte, los agentes religiosos han ido conquistando su protagonismo público, su visibilidad social y se plantean recristianizar el mundo secular en distintas esferas especializadas de la sociedad. Se busca recuperar el binomio simbólico de católicos = mexicanos. Un grupo de abogados católicos aboga en contra de las regulaciones laicistas demandando que el Estado ga- 
rantice la libertad de culto y la expresión religiosa en todos los espacios públicos (incluyendo los medios de comunicación masiva) y en la esfera política. Su propuesta se legitima al retomar algunos modelos de laicidad diferentes al jacobinismo francés que han funcionado en países con una tradición históricamente multirreligiosa o protestante (cuyas condiciones de pluralismo son muy distintas a las de mayoría católica), donde las leyes favorecen a que las iglesias reciban apoyos subsidiarios para sus actividades sociales y a que ingresen como otro actor más en las instituciones educativas y los medios de comunicación. Esta postura se ubica en plantear lo obsoleto de la regulación, por parte del Estado, sobre el actuar religioso en la esfera pública. Se considera que dicha regulación debe reducirse a mantener el equilibrio entre privilegios y restricciones (Giumbelli 2016). Si bien es cierto, el Estado no debe otorgar privilegios a unas religiones por sobre otras, es difícil pensar que en México las instituciones religiosas convivirán en una especie de mercado regulador que garantice las mismas condiciones para todos, pues es un país donde el catolicismo hasta hace poco ha tenido una posición monopólica. Aun en la actualidad, debido a la presencia mayoritaria del catolicismo en México, no considero que sea posible que la diversidad religiosa (siendo minoritaria y diversa internamente) contrarreste el predominio de esta iglesia para lograr la autorregulación. Por ello, no es viable la idea de una regulación del mercado entre los distintos competidores religiosos (como lo sugieren $\mathrm{Ha}$ bermas y otros sociólogos para los casos de países europeos con diversidad religiosa).

\section{Cristianos no católicos: protestantes, evangélicos y pentecostales}

El pentecostalismo en México, al igual que en Latinoamérica, ha ido transformándose (Mansilla 2014, 18). Anteriormente, las iglesias evangélicas tradicionales promovían una identificación popular reconociéndose como "una religión de los pobres, desheredados y estigmatizados" (Mansilla 2014, 13), con una fuerte dosis de ascetismo extramundano -que imprimía reglas estrictas en el vestir femenino, en la conversión como una renuncia a los vicios y tentaciones carnales y de su rechazo a la actividad política y su reforzamiento de modelos de organización comunitarios en torno a líderes mesiánicos y carismáticos (Fortuny 1999, 16), pero esto ha cambiado. En el presente, algunas congregaciones, como la congregación internacional de Asambleas de Dios, han emprendido una guerra espiritual contra el mal que han extendido hacia el ámbito de la política formal. En la actualidad, distintas denominaciones evangélicas establecen su actividad evangelizadora más allá de los templos y se incorporan, o bien se forman partidos políticos y vías clientelares de participar en la política.

En la esfera política, se han establecido las alianzas entre católicos y cristianos conservadores en los últimos años, quienes, a pesar de sus diferencias y desacreditaciones mutuas, organizan cruzadas en contra del matrimonio y la adopción de hijos por personas del mismo sexo, además de hacer frentes comunes en temas como el aborto y los derechos de las mujeres. 
El caso más reciente es el de la ley del matrimonio igualitario (que reconoce el derecho de los homosexuales). Originalmente fue impulsada en el año de 2009 por el PRD en la Ciudad de México, donde se legisló el llamado matrimonio igualitario. Debido a que era una legislación local, no provocó mayores tensiones entre iglesias y Estado, y las disputas se redujeron a la Asamblea Legislativa del entonces Distrito Federal donde se aprobaron tales leyes (Gutiérrez 2017). Siete años después, en 2016, el presidente de México, Enrique Peña Nieto, retomó la iniciativa de matrimonio igualitario que incluía la igualdad de condiciones para adoptar hijos en 2016 basada en la modificación del artículo cuarto de la Constitución Política. Ello provocó múltiples y enérgicas movilizaciones de amplios sectores conservadores, entre las que se incluyen las asociaciones laicales católicas que, por primera vez, establecieron una alianza táctica con evangélicos de Confraternice. Estas movilizaciones fueron lideradas por el Frente Nacional por la Familia en México (2016) ${ }^{3}$ con el objetivo de promover y defender el matrimonio conformado por un hombre y una mujer y a la familia natural. ${ }^{4}$ Este frente convocó a marchas que reunieron a cientos de miles de cristianos en 130 ciudades del país para oponerse a los derechos de las parejas homosexuales al matrimonio y adoptar hijos. Solamente en la ciudad de Guadalajara marcharon 275000 cristianos (fundamentalmente católicos y evangélicos) para reclamar en contra del matrimonio igualitario y la ley de adopción a parejas homosexuales. Se han organizado en bloque para impedir el acceso legislativo a las libertades laicas y derechos sexuales, e incluso por primera vez en la historia, evangélicos y católicos de derecha han dejado atrás su competencia doctrinal y sus diferencias litúrgicas y teológicas para hacer frente común contra lo que han construido como un nuevo enemigo a vencer: "la ideología de género", concepto que ha sido abanderado por movimientos sociales en pro de la conquista de derechos laicos como son la despenalización el aborto, el matrimonio igualitario (entre personas del mismo sexo) y el reconocimiento de las familias inclusivas.

Es también importante considerar la reciente incursión de los evangélicos en la política formal con la fundación del Partido Encuentro Social (PES) cuya "militancia radica principalmente en agrupaciones cristianas evangélicas, aunque defienden el carácter laico del Estado". La razón principal de este impulso consistió en ser un contrapeso a la religión católica. Esta visión del mundo privilegia la defensa de los valores conservadores y se caracteriza como el "partido de la familia", que se opone a políticas liberales como son el matrimonio del mismo sexo, la despenalización del aborto y la libre circulación y venta de revistas pornográficas. En meses pasados, el PES estableció una alianza con el candidato a la presidencia de MORENA (encabezado por Andrés Manuel López Obrador), con el partido de la fracción evangélica PES (correspondiéndole 75 distritos para diputados y 16 para la cámara de senadores), cuyo presidente es Hugo Éric Flores, miembro activo de la Iglesia de Dios y Amistad Cristiana. Algunas promesas de campaña dejaban ver la permeabilidad del discurso pentecostal en la política de AMLO cuando anunció refundar una constitución moral, proyecto que también fue abanderado en Brasil por las bancadas evangélicas.
3. El Frente Nacional por la Familia comprende diversas organizaciones católicas como son Unión Nacional de Padres de Familia, Comité Nacional PROVIDA, Adoración Nocturna, Asociación Nacional Cívica Femenina (ANCIFEM), entre otras. A este frente se sumaron diputados del Partido Acción Nacional (PAN) y simpatizantes el Partido Encuentro Social (PES), órgano político partidista de los evangélicos.

4. Tomado de Frente Nacional por la Familia "Quiénes somos", disponible en www.frentenacional.mx/quiene s somos/ 
El PES logró negociar una gananciosa alianza con Andrés Manuel López Obrador, el candidato a la presidencia de la coalición Juntos Haremos Historia, al ofrecer 15 millones de votantes y argumentar que los evangélicos estaban mal representados en las estadísticas nacionales. Los votos obtenidos fueron menores a los requeridos para mantener su registro como partido político, no alcanzaron a cubrir el mínimo de tres millones de votos y lo perdieron. No obstante, ganaron 75 distritos para diputados y 16 para la cámara de senadores, más de lo que ganó el Partido de la Revolución Institucional (PRI), el más longevo de los partidos y el que ostentó el poder por más de siete décadas que, aunque recibió más votos, no se sumó al candidato ganador.

Aun así, el triunfo de Andrés Manuel López Obrador (AMLO) a la presidencia de la República abre la posibilidad de acceso directo de los pentecostales a la toma de decisiones en las cámaras de diputados y de senadores para, desde ahí, librar la guerra contra el maligno.

Este modelo partidista con bases confesionales pone en riesgo el respeto a la laicidad al convocar al voto clientelista de hermanos evangélicos con la consigna "hermano vota por hermano" (como ya se ha hecho en otros países de Latinoamérica, como han sido los casos de Brasil, Colombia y Costa Rica) para con ello realizar presiones políticas y ganar cuotas de poder. También, han recurrido a presentar a muchos de sus candidatos y candidatas como la mejor opción electoral simplemente porque son evangélicos, y no porque sean competentes o tengan una experiencia profesional para ejercer dicho cargo. Como observó Roberto Blancarte:

El problema es que, al hacer esto, los evangélicos están minando su propia tradición de separación entre asuntos religiosos y políticos (la confusión entre pastores y líderes políticos, o entre "agrupaciones cristiano-evangélicas y partido, son signo de ello) y empujan a que otras agrupaciones religiosas (católicas, evangélicas o de cualquier otra religión) reconfesionalicen el espacio público mexicano. Abren así una caja de pandora, dejando escapar muchos males que creíamos ya superados. Como el de la religión interviniendo en la vida pública" (Blancarte 2014).

Además, la conquista de derechos y libertades laicas había sido impulsada por la izquierda progresista, en particular por el PRD (Partido de la Revolución Democrática), para conquistar leyes que garanticen nuevos derechos individuales, como han sido la despenalización del aborto, el matrimonio entre parejas homosexuales, la adopción por parte de parejas homosexuales. Es- 
tas políticas provocaron enfrentamientos frontales con los obispos católicos, en especial con Norberto Rivera (obispo primado de la diócesis de México) y Juan Sandoval (cardenal de la Arquidiócesis de Guadalajara), quienes han sido las voces oficiales de la iglesia católica en México durante décadas. Un ejemplo de ello fue el desencuentro entre el arzobispo primado de México, Norberto Rivera, y los militantes del PRD, lo cual llegó a ocasionar enfrentamientos. El primero fue en 2009 con la irrupción de los perredistas a una misa en Catedral. Ello se debió a que, estando los seguidores del partido en un mitin en el zócalo de la Ciudad de México, fueron interrumpidos por el tocar de las campanas de Catedral al interpretar ese hecho como un boicot hacia la oradora. Enojados decidieron ingresar a la Catedral metropolitana denunciando al cardenal como opositor al partido, además de que le gritaban "ipederasta!", debido a su encubrimiento de curas acusados de pedofilia. En respuesta, el arzobispo mandó cerrar las puertas de catedral, lo cual en México hace eco a un acto que dio inicio a la Guerra de los cristeros frente al gobierno federal en 1926 (De la Torre 2009).

Las actuales alianzas políticas no van en busca de idearios políticos, sino de conquistar bancadas políticas desde donde impulsar, o bien impedir ciertas leyes contrarias a sus convicciones religiosas. Estas alianzas colocan un nuevo escenario nacional: el de la neutralización de la agenda por las libertades individuales con la alianza partidista entre el Partido Acción Nacional (el PAN es un partido de derecha que tiene vasos comunicantes con asociaciones conservadoras católicas) y el Partido de la Revolución Democrática (el PRD es el partido de izquierda, con fuerte presencia en la capital del país). El PAN ha abanderado el derecho por la vida y la defensa de la familia tradicional en sus campañas y los diputados del PRD fueron quienes aprobaron las leyes de despenalización del aborto y del matrimonio igualitario en la Ciudad de México.

El riesgo es hacer de las cámaras de senadores, de diputados y de los cabildos espacios a ganar por las diferentes posturas ideológicas en torno a los derechos y libertades sexuales. Lo que ha estado ocurriendo recientemente con el avance de los evangélicos en la esfera política en países como Brasil y Colombia no es muy lejano a lo que puede suceder en México con la anunciada alianza del partido MORENA y el PES. Ari Pedro Oro, antropólogo brasileño, advirtió desde hace una década lo que hoy vive Brasil, de la siguiente manera: "el hecho más visible de aproximación entre religión y política consiste en la presencia significativa de iglesias evangélicas, sobre todo pentecostales, en la política, y en la formación de las llamadas 'bancadas evangélicas"' (Oro 2006, 75), que se han infiltrado en los distintos niveles del poder legislativo, donde compiten ahora católicos y evangélicos, pero donde también los extremos conservadores establecen alianzas políticas en la defensa de la ley del orden, emprendiendo cruzadas morales y oponiéndose a leyes que sustentan libertades laicas, como han sido la despenalización del aborto, el divorcio, el reconocimiento jurídico del matrimonio entre sexos iguales y la despenalización de drogas. En 2016, las bancadas políticas evangélicas en Brasil contribuyeron a derrocar a la presidenta Dilma Rousseff 
y tomar el Estado. Un video subido a YouToube muestra que las bancadas políticas evangélicas, ya en el poder, entonaron alabanzas y prédicas cristianas en la sede del cabildo de la ciudad de Río de Janeiro, cuyo alcalde es evangélico, en noviembre de 2017. Estas acciones de transformar recintos gubernamentales en templos cristianos trastocan la autonomía de esferas religiosa y política que requiere la laicidad. Además, si bien es un hecho que las minorías religiosas exigen derechos de libertad religiosa, lo es también que articulan cruzadas en contra del mal, de la brujería y acechan con ejércitos de jóvenes para restringir la libertad religiosa de las religiones populares, indígenas y africanas, a las que combaten como religiones demoniacas (Mariano 2011). Como lo sustenta Corrales:

El ascenso de los grupos evangélicos es políticamente inquietante porque están alimentando una nueva forma de populismo. A los partidos conservadores les están dando votantes que no pertenecen a la élite, lo cual es bueno para la democracia, pero estos electores suelen ser intransigentes en asuntos relacionados con la sexualidad, lo que genera polarización cultural. La inclusión intolerante, que constituye la fórmula populista clásica en América Latina, está siendo reinventada por los pastores protestantes (Corrales 2018).

Estos rasgos no representan al conjunto de las iglesias protestantes ni a las pentecostales; también, han surgido renovados pentecostalismos progresistas que, aunque son minorías, han retomado las demandas de feministas y del movimiento LGBT. Este es el caso de la ICM, una congregación transnacional "inclusiva" que abriga al movimiento LGBT presente en distintos países de América Latina (en especial en México y Brasil). Estas iglesias, si bien son minoritarias, han transformado su identidad doctrinaria y litúrgica en torno a las identidades de la diversidad sexual al flexibilizar sus sistemas morales (Bárcenas 2015). Además, como describiremos más adelante, el conservadurismo no ha permeado a la mayoría de los ciudadanos que, a su vez, suelen ser miembros de una religión.

\section{Percepciones de los mexicanos y creyentes sobre laicidad}

La laicización no solo se logra mediante leyes e instituciones, sino también con la racionalización de la moral (Willaime 1996). Para atender este aspec- 
to, se analizarán los datos ofrecidos por la encuesta ENCREER, RIFREM $2016 .^{5}$

5. La Encuesta ENCREER, RIFREM 2016 fue financiada

La mayoría de los mexicanos $(90,4 \%)$ reconoce que los miembros de cualquier culto religioso deben tener los mismos derechos ciudadanos otorgados por el Estado. También, la mayoría de los ciudadanos se opone a los proyectos de confesionalización del espacio público y aprueba un Estado laico que contemple leyes que regulen la intromisión y acción directa de la religión en el campo político. No obstante, vale la pena acercarnos a estos datos para ver que hay algunos asuntos donde se confirma más la aprobación de la laicidad que en otros.

En el ranking de aceptación de los principios laicos, se encuentra en primer lugar, con $88 \%$, la desaprobación a que los candidatos a elección popular usen símbolos políticos o recursos religiosos para ganar votos; en segundo lugar, la aceptación para que se impartan contenidos de sexualidad en las escuelas públicas con 79,5\%; en tercer lugar, los mexicanos rechazan que las religiones participen abiertamente en política electoral (75,3\%); en cuarto lugar, están de acuerdo con que se imparta contenido de género en los libros de texto escolares (70,7\%); en quinto, $67,9 \%$ se opone a que las iglesias sean propietarias de medios de comunicación; en el sexto puesto, más de la mitad de los mexicanos aprueba leyes que exigen que las iglesias rindan informes fiscales a la Secretaría de Hacienda (56,4\%).

Contrasta con esta radiografía que tres terceras partes (60,6 \%) diga estar de acuerdo con que se impartan contenidos o valores religiosos en las escuelas públicas, pues esta ha sido la institución clave para resguardar un pensamiento laico moderno y lo que no recibe la aprobación de los mexicanos son las tres nuevas preocupaciones de los contingentes conservadores en sus cruzadas contra la "ideología de género": 62 \% se oponen a la despenalización de aborto; 65 \% reprueban la ley del matrimonio mixto (es decir, de parejas del mismo sexo) y $71,7 \%$ están en desacuerdo con la ley que permite a parejas homosexuales la adopción de niños.

Es importante detenernos en estos datos que ponen a hablar a los ciudadanos y, a su vez, creyentes que son frecuentemente silenciados, y que parecen revelar una laicidad subjetiva muy contrastante con la manera en que las cúpulas religiosas, apoyadas por movimientos ultraconservadores, se oponen a que la sexualidad y la "ideología de género" se enseñen en las escuelas. También, muestran un rechazo a que los políticos incorporen los símbolos religiosos, situación que cada vez es más común en las campañas donde los políticos intentan ganar simpatía y credibilidad de los ciudadanos. Asimismo, los datos también confirman que los ciudadanos sí quieren un Estado laico rector de la laicidad que controle el acceso de las religiones en los medios de comunicación y que pida informes de movimientos económicos a las escuelas. Aunque es igualmente importante constatar que la mayoría de los mexicanos coincide con las preocupaciones conservadoras retomadas por algunos grupos católicos y pentecostales.

por CONACYT y aplicada por la empresa Demoskópica, durante el 29 de octubre al 30 de noviembre de 2016 . El cuestionario se aplicó a 3000 casos a fin de obtener un nivel de confianza de $95 \%$ y un error muestral de $\pm 4 \%$ para cada una de las cinco regiones con representatividad estadística y $2,5 \%$ en el caso del conjunto nacional. En la muestra se consideraron trescientos AGEB distribuidos en las 32 entidades del país y se aplicaron 10 cuestionarios en cada una de ellas. Los resultados estadísticos se pueden consultar en Hernández, Gutiérrez Zúñiga y De la Torre 2016, disponible en www.rifrem.mx 
Figura 4. Opiniones sobre laicidad en México. Respuestas a la pregunta: ¿Está usted de acuerdo con las siguientes afirmaciones o situaciones?
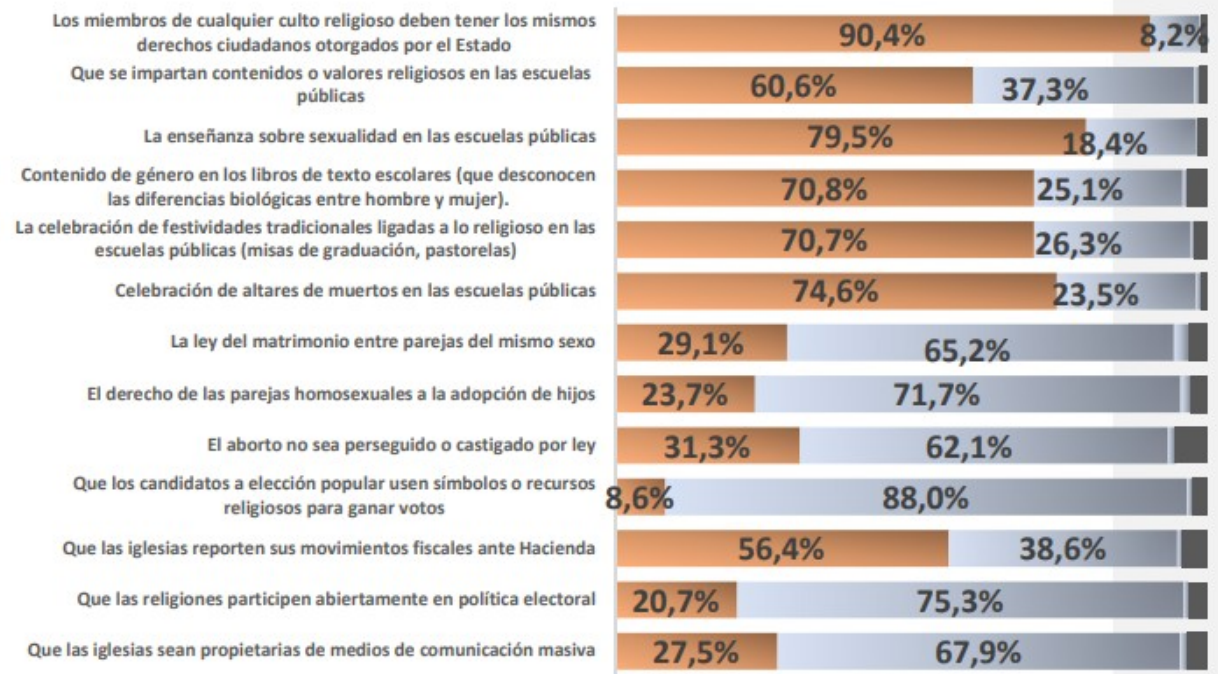

$\begin{array}{lllllllllllllll}0 & 0 \% & 10 \% & 20 \% & 30 \% & 40 \% & 50 \% & 60 \% & 70 \% & 80 \% & 90 \% & 100 \%\end{array}$

así

NO

I NO ME IMPORTA/ ME ES INDIFERENTE/ NO ME INTERESA

- NO SABRÍA OPINAR

Fuente: ENCREER, RIFREM, 2016

Ahora bien, al interior de la población mexicana, podemos apreciar cómo las pertenencias a credos religiosos establecen algunas diferencias significativas en sus posturas asumidas respecto a la laicidad, así como también podemos apreciar aquellos temas donde existen consensos compartidos.

Me concentraré en el comparativo entre población católica y evangélica. En términos generales, se aprecia que los católicos son más liberales con respecto a cuestiones sexuales (20 puntos porcentuales) que los evangélicos. Por ejemplo, mientras una tercera parte (33 \%) aprueba el matrimonio homosexual, solo $8,7 \%$ de los evangélicos lo hacen. Una quinta parte de los católicos $(25,7 \%)$ está de acuerdo con que las parejas del mismo sexo tengan derecho a adoptar niños, en contraste con $8 \%$ de los evangélicos. Y en el tema de la despenalización del aborto, $33 \%$ de los católicos la apoyan frente a $25 \%$ de los cristianos (estos datos se pueden consultar en Hernández, Gutiérrez Zúñiga y De la Torre 2016). 
Figura 5. Comparativo de resultados de opinión sobre laicidad por grupo religioso

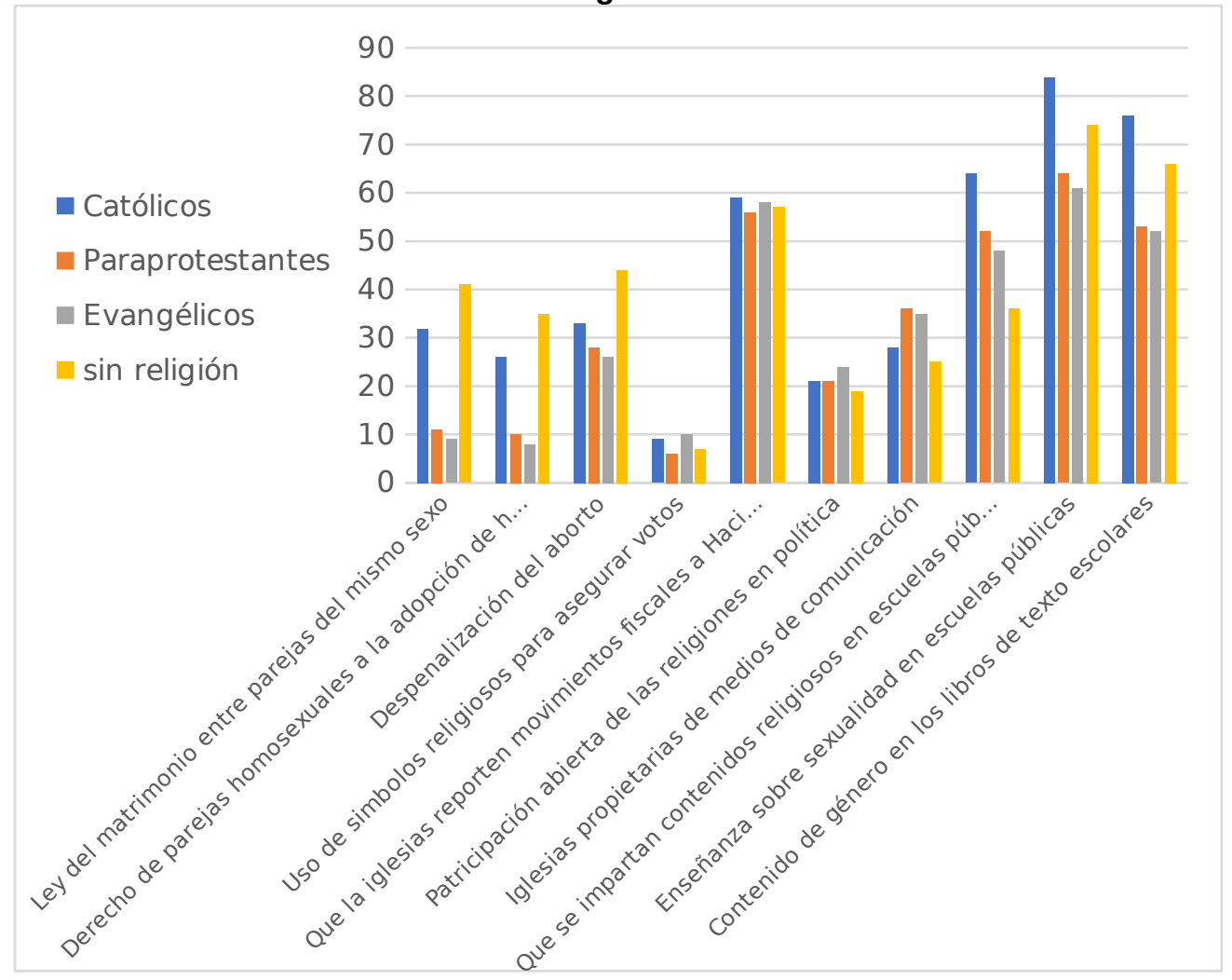

Fuente: ENCREER, RIFREM, 2016

Se debe considerar que el porcentaje de los católicos tiene mayor peso sobre los datos nacionales debido a su estatus de población mayoritaria. Esta radiografía nos muestra que la sociedad, independientemente de sus creencias y adscripciones religiosas, es más secular de lo que pensamos, pues, aunque la mayoría no aprueba las nuevas leyes que otorgan derechos y libertades sexuales, también existe un importante sector que aprueba las nuevas tendencias a la liberación y pluralismo sexual (alrededor de una tercera parte). Otro aspecto por resaltar es que la mayoría de los mexicanos (sin importar credo) se opone al juego político de las religiones en la esfera pública y aprueban el papel regulador del Estado, tanto en el tema de prohibir su incidencia en los medios de comunicación como en que reporten movimientos fiscales. No obstante, las crecientes minorías evangélicas son más conservadoras hacia los asuntos relacionados con la moral sexual que los católicos que representan la mayoría poblacional. 


\section{Conclusiones}

En México el campo religioso es un campo de competencia entre diversas iglesias cristianas minoritarias con la Iglesia católica que sigue gozando de hegemonía y de status mayoritario. Esta nueva situación plantea retos y desafíos para repensar la relevancia de la laicidad en México, que se ve rebasada por el nuevo actuar político de agentes religiosos encabezados por los evangélicos. Lejos estamos de cumplir el triángulo equilátero de la laicidad propuesto por Báuberout (2007). En el caso mexicano, si bien hay un crecimiento que apunta hacia la diversificación religiosa, no se puede hablar de un pluralismo donde, a la manera de Beckford, se atiendan de manera equitativa los reclamos de reconocimiento de minorías relacionados con el trato igualitario a las religiones y el respeto a las creencias y manifestaciones de fe. La creciente presencia ha demandado reformas constitucionales que reconocen la existencia y el derecho jurídico de las asociaciones religiosas, y que buscan ser garantes de los derechos a la libertad de conciencia y de credo religioso mediante una política que impulse el pluralismo en esta materia (Beckford 2003).

En cuanto a la separación Estado-iglesias hemos visto que el crecimiento de denominaciones cristianas no ha contribuido a replegar lo religioso a la esfera privada. Tampoco ha reconvertido las demandas de los agentes religiosos en demandas de derechos humanos. Antes bien ha favorecido a que las iglesias se constituyan cada vez más en actores políticos bajo un modelo corporativo y clientelar. Por un lado, las diferentes religiones son más activas para reclamar reconocimiento por parte del Estado. Por el otro, ingresan en el espacio público organizándose en la sociedad civil para realizar cruzadas en contra del avance de lo que hoy consideran un enemigo a vencer: la ideolo-

6. Este término se usa para etiquetar cualquier esfuerzo por promover la aceptación de la diversidad sexual y de género. Cuando los expertos argumentan que la diversidad sexual es real y la identidad de género es un constructo, el clero evangélico y católico dice que no se trata de algo científico, sino de una ideología. [...] La belleza política de la "ideología de género" es que ha dado a los clérigos una forma de replantear su postura religiosa en términos laicos: como derechos de los padres. En América Latina, el nuevo lema cristiano es: "Con mis hijos no te metas". Es uno de los resultados de esta colaboración entre evangélicos y católicos (Corrales 2018). gía de género. ${ }^{6}$ Esta concepción de riesgo hacia el orden moral patriarcal, ha instaurado inusitadas alianzas entre sectores conservadores de la Iglesia católica y de las Iglesias pentecostales. Las minorías religiosas, así como las minorías conservadoras católicas, son en la actualidad agentes activos que juegan un rol respecto al debate y al avance o retraimiento de los derechos humanos y libertades civiles de los ciudadanos. Desde este frente de oposición amplio las iglesias evangélicas han emprendido una "guerra contra el mal" que las ha llevado a salir de sus templos, no sólo para manifestarse ciudadanamente, sino para conformar una fuerza política mediante la fundación del PES, el partido evangélico mexicano que, está siguiendo el camino en que las Iglesias evangélicas se aproximaron a la esfera política en Brasil mediante la formación de las llamadas 'bancadas evangélicas'" (Oro 2006, 75). De esa manera, aunque son iglesias minoritarias pueden lograr infiltrarse en los distintos niveles del poder legislativo. Lo mismo sucede con los laicos de inspiración católica que abanderan el conservadurismo y que ingresan a la política a través del conservador Partido Acción Nacional (PAN). Al igual que las alianzas establecidas para las campañas moralizadoras, podrán establecer un nuevo bloque conservador en pro de la defensa de "la ley del orden" y en oposición frontal a los reclamos de derechos y libertades laicas, como han 
sido la despenalización del aborto, el divorcio, el reconocimiento jurídico del matrimonio entre sexos iguales y la despenalización de drogas.

Siendo el tercer lado del triángulo la libertad de conciencia y sus consecuencias, la libertad religiosa parece estar garantizada con los avances en materia constitucional que reconoce la libertad de manifestación religiosa a la vez que la existencia jurídica de las asociaciones religiosas. Incluso, como pudimos ver en los resultados de la encuesta ENCREER 2016, existe consenso en que los miembros de cualquier religión deben tener los mismos derechos ciudadanos. No obstante, el avance del bloque cristiano parece ir en la dirección de conquistar bancadas políticas en las cámaras para desde ahí desplegar su "guerra espiritual contra el maligno". Esta estrategia no toma encuentra a los creyentes silenciados cuyas opiniones son opuestas a las de los líderes religiosos conservadores en materia de moral y derechos sexuales. Por otro lado, su estrategia tiende a replegar la libertad de conciencia y los derechos humanos de otras minorías sociales que también pugnan por su reconocimiento y legalización. Sin duda esta situación reta a pensar un renovado Estado laico que pueda ser un actor crucial en la gestión de los valores pluralistas que, por un lado, garantice el reconocimiento y el ejercicio de la libertad religiosa; y, por otro lado, mantenga la autonomía de las decisiones políticas que deben ser tomadas mediante el cálculo de sus consecuencias sociales y el bien común, y no con base en dogmas y preceptos religiosos. Por tanto, se requiere garantizar la autonomía de la gestión del espacio público con respecto a los intereses y creencias particulares de agentes y denominaciones religiosas, sobre todo en áreas primordiales como son la democracia, la salud, las políticas poblacionales y la educación fuera de los intereses particulares de las iglesias y movimientos religiosos.

Este nuevo panorama nos permite advertir que el Estado laico mexicano, famoso por sus estrictas restricciones hacia la acción católica, está siendo rebasado por la diversidad religiosa. Sin duda, estamos ante un nuevo escenario donde los evangélicos ingresan a la arena pública, y el pluralismo religioso demanda reflexionar y proponer nuevas formas de equilibrios que mantengan una laicidad de frente a las recomposiciones religiosas del siglo XXI.

\section{Bibliografía}

Barranco, Bernardo. 2016. Las batallas del Estado Laico: La reforma a la libertad religiosa. Ciudad de México: Grijalbo.

Bárcenas, Karina. 2015. «De los homosexuales también es el reino de los cielos: las iglesias y grupos espirituales para la diversidad sexual y de género en el campo religioso de Guadalajara». Tesis Doctoral. Centro 
de Investigaciones y Estudios Superiores en Antropología Social (CIESAS Occidente).

Bastian, Pierre. 2011. «Las dinámicas contemporáneas de pluralización del campo religioso latinoamericano o cómo pensar de manera relacional una configuración de relaciones objetivas». En Pluralización religiosa de América Latina, editado por Olga Odgers Ortiz, 19-38. Ciudad de México: El Colegio de la Frontera Norte/CIESAS.

Baubérot, Jean. 2007. Les Laïcités dans le monde. París: PUF.

Baubérot, Jean. 2017. «Conclusiones: Laicidad y cultura laica»", en Pauline Capdevielle (coord.). Nuevos retos y perspectivas de la laicidad. Ciudad de México: UNAM, pp. 231-248.

Beckford, James A. 2003. «The Vagaries of Religious Pluralism». Social Theory and Religion, 73-102. Cambridge: Cambridge University Press.

Blancarte, Roberto. 2004. Entre la fe y el poder: Política y Religión en México. Ciudad de México: Editorial Grijalbo.

Blancarte, Roberto. 2008. «Laicidad y laicismo en América Latina». Estudios Sociológicos, 25: 139-164.

Blancarte, Roberto. 2014. «Partido evangélico o con evangélicos». Milenio Diario, 11 de febrero de 2014. (Disponible en http://www.milenio.com/firmas/roberto_blancarte/Partido-evangelicoevangelicos_18_243755642.html. Consultado el 6 de julio de 2017).

Bourdieu, Pierre. 1971. «Génese et structure du champ Religieux». Revue Francaise de Sociologie, 12: 295-334.

Corrales, Javier. 2018. «Un matrimonio perfecto: evangélicos y conservadores en América Latina"». The New York Times, 19 de enero. (Disponible en https://www.nytimes.com/es/2018/01/19/opinionevangelicos-conservadores-america-latina-corrales/. Consultado el 14 de mayo de 2018).

Corten, André, Jean-Pierre Dozon y Ari Pedro Oro. 2003. Les nouveaux conquérants de la foi. L'Église universelle du royaume de Dieu (Brésil), París: Éditions Karthala.

De la Torre, Renée. 2000. Los hijos de La Luz: Discurso, identidad y poder en La Luz del Mundo. Guadalajara: Universidad de Guadalajara / ITESO / CIESAS.

De la Torre, Renée. 2009. «Los laicos en la historia de las relaciones iglesiaestado en México durante el Siglo XX». En Catolicismo y cultura política en América Latina contemporánea, editado por Claudia Touris. Anuario del IEHS, Universidad del centro de la Provincia de Buenos Aires. (N. ${ }^{\circ}$ 24) Buenos Aires: Tandil.

De la Torre, Renée y Cintia Castro. 2011. «El mapa de la diversidad religiosa no católica en el Área Conurbada de Guadalajara en la década de 2000». En Cristina Gutiérrez Zúñiga, Renée de la Torre y Cintia Castro 
(coords.), Una ciudad donde habitan muchos dioses. Cartografía religiosa de Guadalajara, México: El Colegio de Jalisco / CIESAS.

De la Torre, Renée y Cristina Gutiérrez Zúñiga (coords). 2007. Atlas de la diversidad religiosa en México. Ciudad de México: El Colegio de la Frontera Norte / CIESAS / CONACYT / Universidad de Quintana Roo / El Colegio de Michoacán / El Colegio de Jalisco / Secretaría de Gobernación.

Gutiérrez Zúñiga, Cristina y Renée de la Torre. 2015. «Creer, habitar y practicar el territorio: tipos ideales de identidad y residencia en los cristianos no católicos de Guadalajara, Jalisco». Revista Espacialidades, 5(2): 38-76.

Fortuny, Patricia (editora). 1999. Creyentes y creencias en Guadalajara. Ciudad de México: CIESAS//INAH.

Garma, Carlos. 2007. «El pentecostalismo». En Atlas de la diversidad religiosa en México, coordinado por Renée de la Torre y Cristina Gutiérrez, 79-84. Ciudad de México: El Colegio de la Frontera Norte / CIESAS / CONACYT / Universidad de Quintana Roo / El Colegio de Michoacán / El Colegio de Jalisco / Secretaría de Gobernación.

Giumbelli, Emerson. 2016. «Regulação do religioso: discussões conceituais e panorama da situação em quatro países latino-americanos». Ciencias Sociales y Religión/ Ciências Sociais e Religião, Porto Alegre, 18(25): 14-37.

González González, Fernando Manuel. 2001. Matary morir por Cristo Rey: aspectos de la cristiada. Ciudad de México: Plaza y Valdés.

Gutiérrez, Paulo. 2017. «El debate en torno al matrimonio, la familia y los derechos en la Asamblea Legislativa en el Distrito Federal: análisis de un desacuerdo discursivo"». En Rodríguez, Zeyda (coord.). Cultura, discursos y experiencias subjetivas: análisis empíricos en México. Guadalajara: Universidad de Guadalajara.

Gutiérrez Zúñiga, Cristina y de la Torre, Renée. 2017. «Census data is never enough: How to make visible the religious diversity in Mexico». Social Compass. 247-261. Disponible en http://journals.sagepub.com/doi/pdf/10.1177/0037768617697912

Hernández, Alberto, Cristina Gutiérrez Zúñiga y Reneé de la Torre. 2016. Encuesta Nacional sobre Creencias y Prácticas Religiosas en México, RIFREM 2016, Ciudad de México: El Colegio de la Frontera Norte/ CIESAS/EI Colegio de Jalisco www.rifrem.mx

Instituto Nacional de Estadisticas y Geografía. 2010. XII Censo General de $\begin{array}{llll}\text { Población } y & \text { 2010, }\end{array}$ http://www.beta.inegi.org.mx/proyectos/ccpv/2010/ 
Mansilla, Miguel. 2014. La cruz y la esperanza: La cultura del pentecostalismo chileno en la primera mitad del siglo XX. 2. ${ }^{\mathrm{a} e d .}$ Iquique: Manda/Universidad Arturo Prat

Mafra, Clara. 2013. «Números e narrativas». Debates do Ner (24): 13-25. Disponible en http://seer.ufrgs.br/debatesdoner

Mariano, Ricardo. 2011. «Laicidade à brasileira: católicos, pentecostais e laicos em disputa na esfera pública». Cívitas (11): 283-258.

Oro, Ari Pedro. 2006. «Religão e Política no Brasil». En Religião e política no Cone Sul, editado por Ari Pedro Oro, 75-156. São Paulo: Attar editorial.

Salazar, Pedro, Paulina Barrera Rosales, Vladimir Chorny Elizalde, Ana Gaitán Uribe, Javier Martín Reyes y María de Guadalupe Salmorán Villar .2015. La República laica y sus libertades: las reformas a los artículos 24 y 40 constitucionales. Instituto de Investigaciones Jurídicas-UNAM, Ciudad de México.

Weber, Max. 1992. Estado y Sociedad. Ciudad de México: Fondo de Cultura Económica.

Willaime, Jean-Paul. 1996. «Laicté et religión en France». En Grace Davie y Danèle Herveiu-Léger (dirs.). Identités religieuses en Europe, 153-174, París: La Decouverte. 